\title{
A AFETIVIDADE E A EPISTEMOLOGIA GENÉTICA Eixo: Psicologia, Aprendizagem e Educação: aspectos psicopedagógicos e psicossociais
}

Carla Chaves Sousa Andrade Batista

\section{RESUMO}

O presente trabalho se justifica pela importância da afetividade frente ao processo de construção do conhecimento no âmbito da Epistemologia Genética. Pode-se perfeitamente admitir que para a construção do conhecimento do indivíduo, vários autores muitas teorias de aprendizagem foram desenvolvidas com a finalidade de ajudar o profissional da educação na construção do conhecimento do indivíduo, mostrando que são várias as fases de desenvolvimento que a criança atravessa, que cada uma tem seu tempo e forma de aprender, que a afetividade precisa fazer parte deste cotidiano escolar, para que esse aluno não venha sofrer com problemas de ordem emocional, e acabar dificultando o processo ensinoaprendizagem.

Palavras-chave: Afetividade, desenvolvimento, aprendizagem.

\author{
AFFECTIVENESS AND GENETIC EPISTEMOLOGY \\ Axis: Psychology, Learning and Education: psycho-pedagogical and \\ psychosocial aspects
}

\begin{abstract}
The present work is justified by the importance of the affectivity before the process of knowledge construction in the scope of Genetic Epistemology. One can well admit that for the construction of the knowledge of the individual, many authors many theories of learning were developed with the purpose of helping the professional of the education in the construction of the knowledge of the individual, showing that are several stages of development that the child crosses, that each one has its time and way of learning, that affectivity needs to be part of this school routine, so that this student does not suffer from emotional problems, and end up hindering the teachinglearning process.
\end{abstract}

Keywords: Affectivity, development, learning. 


\section{LA AFETIVIDAD Y LA EPISTEMOLOGÍA GENÉTICA \\ Eje: Psicología, Aprendizaje y Educación: aspectos psicopedagógicos y psicosociales}

\section{RESUMEN}

El presente trabajo está justificado por la importancia de la afectividad antes del proceso de conocimiento de la construcción en el ámbito de la Epistemología de la Epistemología. En el caso de que se trate de una obra de arte, se debe a que muchos autores de las teorías sobre el aprendizaje se han desarrollado con el propósito de ayudar al profesional de la educación en la construcción del conocimiento del individual, mostrando que hay varias etapas del desarrollo que el niño cruzado, que cada uno tiene su tiempo y forma de aprendizaje, que la necesidad de ser parte de esta escuela de la escuela, por lo que este estudiante no sufre de problemas de los problemas, y el extremo de indiferencia el aprendizaje de aprendizaje.

Palabras clave: Afectividad, desarrollo, aprendizaje.

\section{INTRODUÇÃO}

A afetividade é um fator importante para o desenvolvimento de uma criança, pois desde a concepção ela precisa se sentir aceita. Os pais, por sua vez, visando à chegada do novo ser, se enchem de ansiedades e expectativas, procurando estruturar a família, que é de fundamental importância para que a criança se sinta assistida, valorizada, amada e segura. Compreende-se então que as relações familiares exercem um papel ordenador para a vida da criança, primeiramente, esta depende inteiramente do organismo da mãe, depois vem o vínculo afetivo, os gestos, os sorrisos, os sinais de contentamento e a dependência para alimentar-se.

A partir daí, a criança começa crescer, passar por suas fases de desenvolvimento, diversificar o meio social. Chega a hora de ir à escola, descobrir um novo mundo, uma nova realidade, buscar relações interpessoais (percebendo a diferença entre o eu e o outro), realizando assim conquistas afetivas que irão alicerçar a construção do eu. 
Sem dúvida que, o meio social (família, escola) em que a criança está inserida, vai promover uma maturidade emocional, pois esta estará interagindo com o seu próximo, e assim desenvolvendo a sua personalidade.

$A$ afetividade e a inteligência têm um papel fundamental na evolução da criança, pois ambas são construídas ao passar do tempo, não são coisas prontas que nascem e ali estacionam. No entanto, a criança ao ser inserida neste novo contexto, deve ter o total apoio e atenção da família, pois educação começa em casa, sem dúvida que, por mais preparada que seja uma escola, a família deve exercer o seu papel, se esta for ausente, a carência afetiva da criança nunca vai ser suprida.

Portanto o presente trabalho se justifica pela importância da afetividade frente ao processo de construção do conhecimento no âmbito da Epistemologia Genética.

Vê-se por tudo que se precede que o professor tem uma função importante na construção do indivíduo, pois o profissional da educação deve passar a ver este ser de forma holística, onde mudanças de comportamento precisam ser redefinidas, deixando de lado posturas egoístas, que têm fragmentado a educação, e passar a ser envolvido pelo mundo dos sentimentos, da criatividade, em que os valores humanos precisam ser respeitados, aproveitando o que já se tem em potencial.

\section{A IMPORTÂNCIA DA AFETIVIDADE NO DESENVOLVIMENTO COGNITIVO}

A afetividade é um conjunto de emoções que influenciam o pensamento e o comportamento. Além disso, a afetividade promove o desenvolvimento da inteligência, regulação emocional e contato social (WADSWORTH, 2005).

A Afetividade, emoções, sentimentos e paixões desempenham um papel importante em nossas vidas. Eles são biologicamente enraizados na nossa natureza. A raiva que expressa desconforto pode servir para nos defender em uma situação perigosa; a ansiedade permite-nos estar em alerta a situações difíceis; a tristeza é uma maneira de expressar a dor dentro de nós, etc (MALDONADO, 1994).

O conceito do Afeto, estritamente falando, é a resposta emocional e sentimental de uma pessoa, a um estímulo ou situação. Em termos gerais, o termo afetividade é geralmente incluído à emoções e sentimentos e paixões. As emoções 
são estados afetivos que ocorrem de repente e drasticamente. Os sentimentos são estados afetivos complexos, estáveis, mais duradouros do que as emoções (DANTAS, 2002).

As maiorias dos autores afirmam que as emoções têm um componente hereditário claro, no entanto, as diferenças na saúde, ambiente familiar e no meio ambiente, podem produzir variações em eventos individuais, tanto em frequência e intensidade e a duração de várias emoções. A emoção influencia ambos os elementos genéticos da porção individual, que são os elementos situacionais de aprendizagem (ANTUNES, 2006).

Educar com afeição é vital para um desenvolvimento emocional e afetivo saudável. As pessoas são seres emocionais por natureza. Nascemos imersos em uma sociedade e estabelecemos laços desde o nascimento e criamos vínculos com nossos companheiros seres humanos. Afetos, portanto, são inerentes as pessoas, é parte de nós (ALARCÃO, 2003).

Embora as afeições permeiem nossos pensamentos e comportamentos e nos fazem experimentar muitas emoções, são facilmente esquecidas quando a educação e até mesmo no nosso dia-a-dia. Nós escondemos nossas emoções, reduzindo nossas amostras e reprimimos sentimentos emocionais, criando uma mistura difícil e estranha que é difícil de definir. Educar com carinho é uma necessidade, é nomear as emoções, para entender nossas ligações e relacionamentos mais íntimos, sabendo como eles nos afetam, e são capaz de expressar e receber esse carinho sem medo (ANTUNES, 2006).

As pessoas aprendem a partir das ações, medos, sentimentos e algumas atitudes por associação, ou seja, por acaso, no tempo e no espaço de vários estímulos que nos fazem estabelecer certos vínculos entre eles e que fazem relacionar no futuro. Nós também aprendemos com os comportamentos de observação, através das ações dos outros. Observação e como se comportar como um lembrete de que temos visto nos outros é algo que orienta nossas ações em muitas situações, e é a explicação que encontramos para comportamentos construtivos ou agressivos (ANTUNES, 2006).

Agora, se nós reconhecemos a importância de aprender através da experiência e da observação é importante, nós também aceitamos o papel nesta fase de desenvolvimento psicossocial e emocional e o grande valor da construção 
de auto-estima e confiança. Sentimentos positivos dão segurança e confiança para o educando e dão importantes pistas sobre se o que ele faz é certo ou errado. Interesse e motivação estão intimamente ligados aos aspectos emocionais, e é motivo de preocupação para os educadores (DANTAS, 2002).

A aprendizagem possui diferentes áreas de desenvolvimento: cognitivo, social, afetivo. O desenvolvimento emocional é claramente situado na família e também deve ser encorajado e cuidados na área da escola. Ele sustenta uma boa adaptação do aluno e contribui para um bom desempenho acadêmico (MALDONADO, 1994).

Mostrar afeto nem sempre é uma tarefa fácil. O tom de voz e tratamento agradável representa um importante passo pelo educador, mas muitas vezes ele se sente tentado a restaurar o bom momento com "um par de gritos." Expressões verbais, manifestações de aceitação, repetição e explicações também ajudam. $O$ rosto demonstra uma manifestação de aceitação e humor; através da expressão do rosto é possível entendermos se fomos bem aceitos (WADSWORTH, 2005).

Para qualquer estudante ter uma melhor recepção de novos conhecimentos é essencial auto-estima, confiança, empatia e disposição positiva para com a aprendizagem. A partir desta premissa, verifica-se que a aprendizagem depende da idade do aprendiz e existem elementos principais facilitadores da aprendizagem, tais como: a empatia, trabalho colaborativo e auto-realização no processo de aprendizagem, o que irá permitir o desenvolvimento cognitivo dos estudantes. Portanto, neste processo deve ser integrado a atividades de promover estes aspectos, facilitando a aquisição, feedback e reforço no conhecimento (DANTAS, 2002).

Demonstrações de afeto são fundamentais para o desenvolvimento saudável. $\mathrm{O}$ desenvolvimento da instituição educacional contemporânea baseia-se na filosofia de mudança, e assenta em três pilares, a saber (DANTAS, 2002): Trabalho em equipe, como um portador de criatividade, qualidade e compromisso nas decisões e ações dos professores; A cultura axiológica de todos os agentes educativos, tais como os valores comuns que transformam a instituição condição necessária educacional e resultado do desenvolvimento institucional, ou seja, a formação e competências de cidadania e a liderança pedagógica como a 
ferramenta fundamental para alcançar as metas propostas na educação dos nossos alunos.

De acordo com Goleman (1995) as mudanças tão dinâmicas que ocorrem na sociedade deve desenvolver uma educação saudável diferente, formação espiritual, uma pedagogia de afeto, em suma, um educação do coração, que é o relógio da alma. Por isso, é importante compreender e reconhecer, e fazer uma auto-análise crítica que a primeira marca que a escola possui, a televisão, a família e a sociedade em geral, impressa na alma da criança é a competição.

Muitas são as reflexões no que diz respeito à afetividade e inteligência na construção do conhecimento no âmbito da epistemologia genética, pois o indivíduo precisa ser visto como um ser completo. "Wallon considera a pessoa como um todo. Afetividade, emoção, movimento e espaço físico se encontram num meso plano" (apud MARIA PIRES RELVAS, 2008, p.108).

$A$ afetividade exerce uma influência muito grande no desenvolvimento infantil, pois no ambiente a qual está inserida rebela-se níveis de maturação, quer de ordem interna ou de ordem social. Laterrasse (1981) afirma que Wallon formulou uma teoria de origem da afetividade definida como teoria da emoção e do caráter (APUD Almeida, 1999, p.41). Enquanto que Almeida (1999), comentando uma obra de Wallon, afirma que,

\footnotetext{
Antes de tudo, devemos saber que a personalidade, é constituída basicamente por duas funções: a afetividade $e$ a inteligência. $E$ conseqüentemente o processo de personalização depende da evolução dessas duas componentes. A palavra personalidade é considerada (...) no sentido do ser total físico-psíquico e tal como ele se manifesta pelo conjunto do seu comportamento. (WALLON, 1963, p.73)
}

A afetividade e inteligência caminham juntas, elas não estão prontas, também não são inatas, são construídas ao longo do desenvolvimento, se modificam de um período a outro. À medida que o sujeito cresce, as necessidades afetivas tornam-se cognitivas. Segundo Almeida "a evolução da inteligência é incorporada pela afetividade de tal modo que uma determinada relação afetiva evolui para outra" (1999, p. 51).

Para Piaget (apud BALESTRA, 2007), a afetividade e a inteligência são, portanto, indissociáveis e constituem os dois aspectos complementares de toda conduta humana (p.47). 
Na obra Walloniana, a afetividade e a inteligência constituem um par inseparável na evolução psíquica, pois ambas têm funções bem definidas e, quando integradas, permitem à criança atingir níveis de evolução cada vez mais elevados.

O desenvolvimento da inteligência em grande parte é função do meio social. Para que ele possa transportar o nível da experiência ou da invenção imediata e concreta, tornam-se necessários os instrumentos de origem social, como a linguagem e os diferentes sistemas de símbolos surgidos desse meio. Constituem seus objetos a aquisição ou o desenvolvimento de noções e de conhecimentos existentes fora do indivíduo e que representam o patrimônio do grupo (WALLON, 1993, apud ALMEIDA, 1999, p.51).

A habilidade emocional é uma coluna simples, porém grande no sustentáculo da educação, pois a mesma precisa de tempo para ser trabalhada, e o afeto se enquadra neste contexto de habilidades emocionais. Edgar Moran ainda contribui com:

A afetividade pode asfixiar o conhecimento, mas pode também fortalecê-lo. Há estreita relação entre inteligência e afetividade: a faculdade de raciocinar pode ser diminuída, ou até mesmo destruída, pelo déficit de emoção; o enfraquecimento da capacidade de reagir emocionalmente pode mesmo estar na raiz de comportamentos irracionais. (MORAN, 2000, p.20)

Dessa forma, a afetividade e a inteligência se estendem no decorrer do desenvolvimento do sujeito, à medida que a inteligência passa por novos estágios, a afetividade vai se racionalizando, pois ambos estão interligados. No momento que o educador transmite conhecimentos, está paralelamente transmitindo conceitos de aspecto cognitivo e afetivo. Desse modo a evolução e a maturação deste ser se completa de acordo com a reciprocidade de ambos.

Durante o desenvolvimento de uma criança, ela passa pela infância, que é a idade das brincadeiras, e por meio delas a criança satisfaz em grande parte, seus interesses, necessidades e desejos particulares; é a forma de inserção na realidade, pois expressa a maneira como a criança reflete, ordena, desorganiza, destrói e reconstrói o mundo.

Para Winnicott (apud ÁRBILA LUIZA ARMINDO ASSIS, 2007),

...o brincar equivale a uma terapia. Tanto é que descreve psicoterapia como sendo duas pessoas que brincam juntas: o paciente e o psicoterapeuta. $O$ brincar é sempre uma experiência essencial para a vida, criativa e real para a criança que brinca, podendo até tornar-se assustadora para ela, inclusive porque mobiliza seus conteúdos inconscientes (p.76) 
O lúdico permite um desenvolvimento global e uma visão de mundo mais real. Criando e descobrindo, a criança pode se expressar, analisar, criticar e transformar a realidade.

A ludicidade é uma necessidade do ser humano em qualquer idade e não pode ser vista apenas como diversão. O desenvolvimento do aspecto lúdico facilita a aprendizagem e o crescimento pessoal, social e cultural e colabora para a boa saúde mental e física.

Na perspectiva de Vygostsky, a criança inserida no social é produto de um contexto cultural, facilitando a exploração do imaginário, da memória e o registro de suas experiências.

É através das brincadeiras e dos jogos que a criança interage com o seu meio. O brincar é uma atividade cotidiana na vida das crianças. Através do brincar elas resolvem a maioria dos seus conflitos criados pela limitação do mundo em que vive.

À medida que cresce, com as imagens que já se formaram na sua mente a criança utiliza-se do jogo simbólico para criar significados para objetos e espaços.

Kishimoto (2000, p.19) afirma que: O brinquedo propõe um mundo imaginário da criança e do adulto, conforme a idade: para pré-escolar de 3 anos, está carregado de animismo: de 5 a 6 anos, integra predominantemente elementos da realidade.

Isso afirma que os educadores necessitam conhecer melhor os comportamentos das crianças de acordo com as etapas do desenvolvimento, pois estas podem ser caracterizadas por uma estrutura de desenvolvimento mental, onde os aspectos motor, intelectual e afetivo são apresentados. Piaget (apud BALESTRA, 2007, p.55), através da pesquisa psicogenética caracterizou a formação das estruturas intelectuais dividindo-as em quatro estágios: estágio da inteligência sensório-motora, estágio da inteligência simbólica ou pré-operatória, estágio da inteligência operatória concreta e estágio da inteligência formal.

Na relação professor-aluno, o professor detém o conteúdo (não o saber total), transmitindo ao aluno o interesse pela busca de novos conceitos e realidades. Seu papel neste contexto é de mediador e facilitador do processo de ensinoaprendizagem, pois cada aluno possui o seu ritmo de aprendizagem, e necessário se faz que sejam respeitadas as diferenças individuais. A relação de amizade, 
respeito, cooperação, sem deixar de aplicar os conteúdos, é muito importante para a construção dos conhecimentos.

Para Maria Marta Bazaro Balestra, 2007, na teoria piagetiana,

\begin{abstract}
...Essa postura lhe permite pensar (e demonstrar através da sua prática em sala de aula) que existem diferentes maneiras de aprender e de expressar um mesmo conhecimento, pois é considerado um profissional que conhece com profundidade o conteúdo que se propõe a ensinar; e ensinar significa socializar o conhecimento com os alunos através de procedimentos cooperativos.

Nessa linha de pensamento, a suposição é que, ao mesmo tempo em que se ensina, o professor está sempre atento para analisar as diferentes maneiras de aprendizagem demonstradas pelos alunos na execução das atividades propostas. Agindo assim, descobre novas estratégias de ensino, adequandoas àquelas que fazem parte do seu cotidiano e ampliando o leque do seu próprio saber, ou seja, o SABER-ENSINAR-SABER-APRENDER (p.102)
\end{abstract}

$\mathrm{Na}$ sociedade atual, comportamentos de professor detentor absoluto do saber, não podem mais existir, pois a interação é o ponto forte. O professor deve ser um investigador, que questiona o aluno, e ambos interagem e aprendem juntos. Os professores e pais devem valorizar os esforços e atitudes de cada criança, pois seu rendimento depende muito do convívio dentro e fora do ambiente escolar. Os alunos precisam sentir-se motivados, com elogios pelo sucesso e estimulados a persistirem em seus esforços, pois um indivíduo só se torna completo quando encontra-se motivado. Para Woolfolk (2000), "motivar significa encorajar seus recursos interiores, seus sensos de competência, auto-estima, autonomia e autorealização".

Partindo desse pressuposto, os indivíduos que se sentem incentivados e motivados, as inteligências podem ser desenvolvidas com mais facilidade, pois estão sendo estimuladas, daí a necessidade do educador ter a mente aberta, e estar disposto a se adequar às mudanças, ser participativo e exercer um papel importante na construção do conhecimento da criança. Portanto, para se alcançar bons resultados pessoais ou organizacionais, deve-se compartilhar o interesse em atingir o mais alto nível de qualidade nos serviços oferecidos, e isso se consegue por meio do trabalho em conjunto. Nessa relação interpessoal, deve-se estar interagindo com o grupo, pois assim terá mais criatividade, novos arranjos de idéias, trocar conceitos já formados, buscar novas iniciativas, para obter resultados de grande valor para cada indivíduo. 
O professor deve tratar todos os alunos da mesma forma, sem preconceitos (raciais, religiosos, gênero, etc.), reconhecer todos pelo nome, deixar transparecer uma afetividade igual, mostrando assim interesse na aprendizagem do aluno. De acordo com a teoria piagetiana, o desenvolvimento afetivo se dá paralelamente ao desenvolvimento cognitivo.

Para Paulo Freire (1996, p.41)

Ensinar exige querer bem aos educandos. Não é certo, sobretudo do ponto de vista democrático, que serei tão melhor professor quanto mais severo, mais frio, mais distante e "cinzento" me ponha nas minhas relações com os alunos.

Assim, cabe ao professor compreender a influência que exerce sobre o aluno, e entender que os diversos comportamentos apresentados por eles podem ser de ordem emocional. Ensinar e educar são desafios cada vez mais difíceis, diante dessa realidade, a sociedade atual requer professores que saibam lidar com essas pessoas e sua realidade de vida, tornando-as capazes de viver dignamente em sociedade.

\section{CONSIDERAÇÕES FINAIS}

O aluno de uma forma geral precisa ser visto como ser único, que tem sentimentos e emoções, e estes se não forem tratados de forma sublime e respeitosa poderão sofrer durante toda sua vida, pois, as pessoas até chegarem à adolescência precisam se sentir seguras, apoiados em alguém que thes dêem suporte, porque é nessa fase que se dá o desenvolvimento cognitivo, afetivo, social e moral. Somente a partir da adolescência, que o indivíduo começará a enxergar o mundo de outra forma, pois a maturidade moral só pode ser alcançada na fase adulta.

Durante o desenvolvimento da inteligência infantil, novas posturas precisam ser adotadas pelo professor, pois, cada aluno tem tempo e formas diferentes de aprender, e mesmo diante das dificuldades de aprendizagem é necessário enfatizar o papel do prazer e da função primordial da auto-estima. Esta profissional, também deve ter em mente que o lúdico é um grande laboratório que merece a atenção dos pais e dos educadores, pois é através dele que ocorrem experiências inteligentes e 
reflexivas praticadas com emoção, prazer e seriedade. Através das brincadeiras é que ocorre a descoberta de si mesmo e do outro.

Dessa forma, pode-se perfeitamente admitir que para a construção do conhecimento do indivíduo, vários autores desenvolveram teorias que visam ajudar o profissional da educação na construção do conhecimento do indivíduo, mostrando que são várias as fases de desenvolvimento que a criança atravessa, que cada uma tem seu tempo e forma de aprender, que a afetividade precisa fazer parte deste cotidiano escolar, não importando a fase, desde a Educação Infantil até o Ensino Superior, para que laços afetivos sejam estreitados e esse aluno não venha sofrer com problemas de ordem emocional, dificultando o processo ensino-aprendizagem.

\section{REFERÊNCIAS:}

ALMEIDA, Ana Rita Silva. A emoção na sala de aula. Campinas: Papirus, 1999.

ASSIS, Árbila Luiza Armindo - Influências da psicanálise na educação: uma prática psicopedagógica. 2 ed. Ver. - Curitiba: Ibpex, 2007.

BALESTRA, Maria Marta Mazarro. A psicopedagogia em Piaget: uma ponte para a educação da liberdade. - Curitiba: Ibpex, 2007.

CHALITA, Gabriel - Educação: A solução está no afeto. - São Paulo: Ed. Gente, 2001, 1 ed., 2004, edição revista e atualizada.

CHALITA, Gabriel - Pedagogia do Amor. - São Paulo: Ed. Gente, 4 ed., 2003, edição revista e atualizada.

COLL, C., MARCHESI, E PALACIOS, J.; trad. ALVES, Angélica Mello. Desenvolvimento psicológico e educação. Porto Alegre: Artes Médicas, 1996.

COLL, C., MARCHESI, E PALACIOS, J.; trad. MURAD, Fátima. Desenvolvimento psicológico e educação. 2ed. Porto Alegre: Artes Médicas, 2004.

CURY, Augusto - Filhos brilhantes, alunos fascinantes, - Colina - SP: Ed. Academia de Inteligência, 2006.

CURY, Augusto - Pais brilhantes, professores fascinantes - Rio de Janeiro: Sextante, 2003.

GOLEMAN, Daniel. Inteligência Emocional. Rio de Janeiro: Objetiva, 1996.

GRASSI, Tânia Maria. Psicopedagogia: um olhar uma escuta. - Curitiba: Ibpex, 2009. 
FACION, José Raimundo - Transtornos invasivos do desenvolvimento e transtornos de comportamento disruptivo/ José Raimundo Facion. - Curitiba: IBPEX, 2005. 148p.

FERREIRA, Aurélio Buarque de Holanda- Miniaurélio Século XXI. 5 ed. Ver. Ampliada. - Rio de Janeiro: Nova Fronteira, 2001.

FREIRE, Paulo - Pedagogia do oprimido, 17 ed., Rio de Janeiro, Paz e Terra, 1987.

FREIRE, Paulo - Pedagogia da Autonomia: saberes necessários à prática educativa,/ Paulo Freire. 30 ed., São Paulo, Paz e Terra, 1996.

FREITAS, Nilson Guedes de - Pedagogia do amor: Caminho da libertação na relação professor-aluno. Wak, $2 \mathrm{Ed}$.

LAKOMY, Ana Maria. Teorias cognitivas da aprendizagem. 2ed. rev.e atual.Curitiba: Ibpex, 2008.

MALPASS, Leslie F., HOCUTT, Max O., MARTIM, Edwim P., GIVENS, Paul R., MARQUES, Juraci C.(Tradutor) - 0 comportamento humano, 2 ed. - Rio de Janeiro - Ed. Renes, 1970.

MALUF, Ângela Cristina Munhoz - Brincar: prazer e aprendizado. Petrópolis, RJ: Vozes, 2003.

MOSCOVICl, Felá - Desenvolvimento interpessoal - Treinamento em grupo - 8 ed. - Rio de Janeiro: José Olympio, 1998.

MORAN, Edgar - Os sete saberes necessários à Educação do Futuro. 2 ed. São Paulo: Cortez; Brasília, DF: UNESCO, 2000.

OLINTO, Antonio, 1919- Minidicionário Antonio Olinto da língua portuguesa/ Antonio Olinto. - 2. ed.ver. e ampl. - São Paulo: Moderna, 2001.

PALANGA, Isilda Campaner. Desenvolvimento e aprendizagem em Piaget e Vigotsky: a relevância do social. 3 ed. São Paulo: Summus, 2001.

RELVAS, Marta Pires - Fundamentos biológicos da Educação: despertando inteligências e afetividade no processo de aprendizagem. - 3. Ed. Rio de Janeiro: Wak ED., 2008.

ROMANOWSKI, Joana Paulin. Formação e profissionalização docente. 3ed. rev. e atual.- Curitiba: Ibpex, 2007.

SAMPAIO, Dulce Moreira. A Pedagogia do Ser - Educação dos sentimentos e dos valores humanos. Petrópolis: Vozes, 2004. 
SMOLE, Kátia Cristina Stocco - Múltiplas Inteligências na Prática Escolar/ Kátia Cristina Stocco Smole- Brasília: Ministério da Educação. Secretaria de Educação à Distância, 1999, 80p.; 16 cm. (cadernos da TV Escola. Inteligências Múltiplas, ISSN 1517- 2341 n.1)

TIBA, Içami - Disciplina, limite na medida certa. São Paulo: Ed. Gente, 1 ed., 1996.

TIBA, Içami - Ensinar aprendendo: como superar os desafios do relacionamento professor-aluno em tempos de globalização. São Paulo: Ed. Gente, 1998.

TREVISAN, Rosi Mary Soares. Formação e Profissionalização do Psicopedagogo. Curitiba: IBPEX, 2003. 